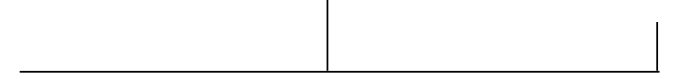

Rev. Latinoam. Psicopat. Fund., São Paulo, v. 12, n. 4, p. 731-742, dezembro 2009

\title{
A bilionária indústria da educação médica continuada nos EUA: mais uma forma de interferência das empresas na relação médico-paciente
}

Mônica Teixeira

$O$ artigo trata de mais uma das formas pelas quais a indústria impacta a clínica médica. A indústria farmacêutica e de dispositivos médicos financia atividades de Educação Médica Continuada com o objetivo de promover a utilização de tratamentos que a ela interessam. A Educação Médica Continuada é obrigatória em muitos estados dos EUA para a renovação da licença para o exercício de profissões médicas e para-médicas. O congresso dos EUA discute como regular a questão, no contexto da reforma do sistema de saúde posta em discussão pelo atual presidente do país.

Palavras-chave: Indústria farmacêutica, educação médica, relação médico-paciente 
O tema Educação Médica Continuada entrou na pauta de duas comissões do Senado dos EUA. É por meio de Continuing Medical Education que médicos e enfermeiras no país mantêm sua licença para exercer a profissão ao longo dos anos de carreira. Mais: de acordo com a visão predominante no Congresso a respeito da boa prática da medicina, é essencial que os profissionais se mantenham atualizados e informados sobre o "avanço do conhecimento" para que possam cuidar da melhor maneira possível de seus pacientes.

No jargão dos documentos reunidos pelas comissões do Senado que "Observando a Medicina" pesquisou, educação médica continuada atende pelas iniciais CME, da expressão em inglês. A atenção dos senadores voltou-se para a CME pelo fato de as atividades compreendidas como tal terem se tornado, nesta década especialmente, terreno em parte ocupado por companhias farmacêuticas, de biotecnologia, e fabricantes de dispositivos médicos. Dados da instituição que credencia entidades que oferecem CME - o Conselho de Credenciamento para Educação Médica Continuada, ACCME, Accreditation Council for Continuing Medical Education - mostram que, em 2007, a indústria farmacêutica gastou mais de um bilhão de dólares para cobrir mais da metade dos custos das atividades de CME no país, naquele ano. ${ }^{1}$

\section{"Pesquisa e educação médicas: aprendizado superior ou ganho superior?'}

A pergunta foi o título escolhido para uma audiência da Comissão Especial do Senado sobre o Envelhecimento, organizada para o dia 29 de julho de 2009. O senador Herb Kohl, que presi-

1. Accreditation Council for Continuing Education. ACCME Annual Report Data 2007 (2008). 
de a Comissão, colocou assim a questão sobre a participação da indústria na educação dos médicos:

Nos anos recentes, a indústria de medicamentos e de dispositivos médicos tem se envolvido cada vez mais no financiamento da educação dos médicos. Centros médicos acadêmicos e escolas médicas apoiam-se cada vez mais no financiamento da indústria para seus programas de educação e de pesquisa. O financiamento de CME pela indústria quadruplicou na última década, e agora é de mais de US\$ 1 bilhão por ano. Enquanto aumentou o escrutínio do Congresso e da mídia sobre as relações financeiras entre médicos e essas indústrias, esse tipo de financiamento indireto é a última fronteira.

É caro oferecer formação e acesso às inovações médicas mais recentes, para dizer o mínimo dos recursos necessários para apoiar a pesquisa, em primeiro lugar. Hospitais de ensino e escolas médicas enfrentam também custos crescentes. Dessa perspectiva, o financiamento pela indústria preencheu uma necessidade real. Mas, como sabemos, grandes corporações não gastam essas somas a menos que eles pensem que vão obter alguma coisa em troca. Isto não é uma acusação à indústria, é apenas como negócios funcionam.

Isto nos leva à questão crucial da audiência de hoje. A indústria de medicamentos e de dispositivos está obtendo retorno pelo seu investimento anual de US\$ 1 bilhão em educação médica? Os programas financiados pela indústria permanecem fiéis à missão de fornecer educação e pesquisa imparciais, ou ao invés disso servem à promoção dos últimos produtos da indústria?

\section{Antecedentes, dos jornais}

Em 3 de setembro de 2009, jornais de todo o mundo noticiaram: "Pfizer paga US\$ 2,3 bilhões em Acordo sobre Comercialização" - para usar o título do texto do New York Times escrito por Gardiner Harris, repórter que acompanha os movimentos na área da saúde. Como ela esclareceu, o pagamento foi "o maior em um acordo de fraude em serviços de saúde e a maior multa da história em casos criminais". E por que a Pfizer foi penalizada? Por ter se declarado culpada (antes de a investigação chegar ao fim) em ações em que ela mesma e a subsidiária Pharmacia \& Upjohn foram acusadas de realizar promoção ilegal de quatro medicamentos - inclusive o Bextra. O Bextra foi um dos antiinflamatórios retirados de circulação por causarem efeitos adversos não previstos pelo FDA, a agência que controla a comercialização de medicamentos nos EUA. Mas a ilegalidade cometida pela Pfizer e subsidiária não residia nesse problema do medicamento, mas 
sim na prática de propagandear o chamado uso off label junto a médicos e outros profissionais de saúde. Off label quer dizer: fora da bula. Ao autorizar a comercialização de uma droga, o FDA estabelece para que usos ela pode ser prescrita, que constam na bula.

Companhias farmacêuticas não podem promover o medicamento indicando usos fora do estabelecido na bula. Não podem, mas fazem, com o objetivo de impulsionar as vendas, pois embora as empresas não possam fazer propaganda do uso fora da bula, os médicos podem prescrevê-la da maneira que acharem melhor para seus pacientes. Ao fazê-lo, os laboratórios farmacêuticos - como a Pfizer - incorrem em crime; e também em fraude contra o sistema de saúde. O resultado da promoção ilegal do medicamento, além dos aspectos propriamente relacionados à saúde dos pacientes, é também acréscimo nos gastos nos programas públicos de assistência aos mais pobres, o Medicaid, e maiores de 65 anos, o Medicare. "Conduta ilegal e fraude por companhias farmacêuticas põem a saúde pública em risco, corrompe decisões médicas por fornecedores, e custa ao governo bilhões de dólares", disse um promotor do Ministério da Saúde no dia do anúncio das penalidades da Pfizer.

Na notícia oficial sobre o caso - em que se afirma que o valor da multa foi calculado em proporção ao fato de a empresa já ter sido apanhada (antes), por três vezes, em atividades de promoção off label -, o governo relaciona os órgãos envolvidos na perseguição à empresa: os escritórios dos promotores públicos de Massachusetts, da Pensilvania, do Kentucky; uma divisão de causas cíveis do Ministério da Justiça; o Escritório do Inspetor Geral do Ministério da Saúde; o FBI; o Escritório de Investigações Criminais do FDA - entre outros. As companhias farmacêuticas estão, portanto, sob detalhado e continuado escrutínio (como "Observando a Medicina" mostrou em "O cerco à indústria farmacêutica nos Estados Unidos", na edição de junho de 2003 desta revista); e a "última fronteira" da promoção do uso off label, para usar a expressão - e a suspeita - do senador Herb Kohl, parece estar na instrumentalização de atividades de educação médica continuada.

\section{Educação não é marketing}

Para Lewis Morris, que depôs perante a comissão do senado em nome do Escritório do Inspetor Geral do Ministério da Saúde (chamado Departamento da Saúde e dos Serviços Humanos, na tradução literal), o caminho para preservar o limite entre educação e marketing no país passa por "aperfeiçoar salvaguardas". A afirmação, que aparece no início da fala lida durante a audiência, ecoa um de- 
bate em curso entre envolvidos, sobre banir ou não qualquer patrocínio da indústria em atividades de CME. O Ministério da Saúde não endossa o banimento, ao menos imediatamente, e acredita no aperfeiçoamento das regras de salvaguardas. Faz parte do acordo com a Pfizer, por exemplo, um amplo programa para "revisão de procedimentos" internos à companhia que, no entender do governo, ajudará a evitar a repetição das ilegalidades.

Morris não vê contradição fundamental entre os interesses propriamente médicos e os interesses comerciais - embora os médicos devam ter como primeira prioridade o bem-estar de seus pacientes e para isso usem a educação continuada; enquanto, do lado da indústria, as prioridades estejam em aumentar a participação de seus produtos no mercado e maximizar o lucro dos acionista e o patrocínio de atividades de educação continuada ser um "meio efetivo para alcançar esses objetivos de negócios”. É essa característica do interesse da indústria que torna "essencial" o estabelecimento de salvaguardas para "garantir que a CME fique livre de viés comercial". Ele cita um estudo de $2001^{2}$ que calculou em US\$ 3,56 o retorno para cada US\$1,00 investido em CME pelas companhias farmacêuticas e de dispositivos médicos.

Um dos méritos da apresentação de Morris é oferecer uma visão geral do funcionamento da CME. Na segunda parte de seu statement, ele explica como funciona a supervisão da CME no país. A já mencionada ACCME credencia organizações e empresas que desejem oferecer educação médica continuada; após o credenciamento, não é requerido ao credenciado que apresente seus programas para revisão ou aprovação. Dados de 2007, do relatório já citado, mostram haver 736 credenciados, dos quais 150 são companhias de educação médica com fins lucrativos. Essas empresas, e qualquer credenciado (hospitais, escolas médicas, organizações sem fins lucrativos), tem permissão da ACCME para oferecer atividades de CME diretamente financiadas pela indústria. Nesta "fronteira", depreende-se, as companhias estão à vontade - quase completamente à vontade: há algumas exigências a serem seguidas. Como exemplo, Morris cita: o conteúdo da CME deve estar "livre do controle de um interesse comercial". É muito limitado, critica o funcionário do Ministério da Saúde: "nove anos podem se passar entre a identificação de uma atividade de CME desconforme à exigência e a revogação de seu credenciamento pela ACCME”. O resultado é aquele indicado pelo senador na abertura dos trabalhos (e de que maneira seria outro?): "CME patro-

2. Scott Neslin, Roi Analysis of Pharmaceutical Promotion (RAPP): An Independent Study (May 22, 2001). Available online at <http://www.rxpromoroi.org/rapp/media/slides_peakernotes.pdf $>$. 
cinada pela indústria cobre quase exclusivamente tópicos relacionados a produtos comerciais, ao invés de discussões mais amplas sobre o tratamento dos pacientes".

\section{Ao arrepio da lei}

Para calcular quanto a prescrição off label representa para o faturamento da indústria, Morris recorre a um estudo de $2006,{ }^{3}$ que estimou o número em $21 \%$ das vendas de medicamentos que requerem receita médica. É bastante; mas como demonstra o exemplo da Pfizer, a companhia que faz isso por meio de seus promotores de vendas corre o risco de ser apanhada e penalizada. No entanto, embora o marketing do uso off label pela indústria seja ilegal, não é expressamente proibido que atividades de CME, patrocinadas por empresas do setor, discutam o uso off label de medicamentos, dispositivos ou outros produtos biomédicos.

A brecha é grande e atrativa para a indústria. Mas não as deixa livres do braço da lei: se for constatada a manipulação da atividade de CME com o objetivo da promoção off label, então a mesma legislação que atingiu a Pfizer atinge a empresa que patrocina a manipulação - é a Lei de Alimentos, Drogas e Cosméticos que torna crime a promoção de um produto para além do uso proposto pela empresa ao pedir autorização para sua comercialização junto ao FDA. É no âmbito do pedido que o FDA analisa e autoriza a comercialização. Um exemplo do alcance do braço da lei: a empresa Orphan Medical pagou US\$ 20 milhões para não ser processada por marquetear Xyrem, autorizada pelo FDA para tratar narcolepsia, para outras indicações. A empresa usou para isso supostos "programas independentes de CME", em que um psiquiatra (que recebeu "milhares de dólares") falava a médicos sobre outras indicações do Xyrem. O caso ganha gravidade adicional porque Xyrem, conhecido entre jovens como GHB, é usado como droga recreacional. Outras duas legislações podem ser usadas quando constatada a manipulação da educação médica pela indústria: o "False Claims Act" - em que a promoção do uso off label, como no caso da Pfizer, é caracterizado como fraude contra o sistema público de saúde; e o chamado "estatuto contra gorjetas", que tipifica como crime, por exemplo, o pagamento ao psiquiatra que propagandeou o uso off label do Xyrem. Em geral, o governo prefere perseguir os pagadores e não os recebedores desse dinheiro.

3. David C. Radley, Stan N. Finkelstein \& Randall S. Stafford. Off-Label Prescribing Among Office-Based Physicians, 166 ARCHIVES OF INTERNAL MED. 1021-1026 (2006). 
O Conselho de Ética da Associação Médica Americana propôs, em 2009, ser "eticamente preferível que quem oferece Educação Médica Continuada só aceite financiamento de fontes que não tenham interesse comercial direto na recomendação clínica dos médicos". ${ }^{4} \mathrm{O}$ governo, no entanto, vê problemas práticos na proposta: com que financiamento as empresas que oferecem CME vão continuar o trabalho?, pergunta o Escritório do Inspetor Geral. Em lugar do banimento do patrocínio das companhias interessadas em produtos médicos, o Inspetor Geral sugere que a) as companhias separem, em suas estruturas, as atividades de vendas e promoções das atividades de financiamento de atividades de CME; b) que se estabeleçam critérios objetivos para o financiamento de atividades de CME, de maneira a claramente evitar uso ilegítimo desses fundos; c) a eliminação de qualquer controle por parte dos patrocinadores do conteúdo ou da seleção de speakers em atividades de CME. Outras sugestões incluem, por exemplo, criar fundos para receber financiamento, que os distribuam depois para as empresas que organizam CME.

Um resultado possível de mais salvaguardas, diz Lewis Morris, é as companhias do setor médico se retirarem do financiamento da educaçao continuada. Se isso acontecer, os médicos terão que pagar eles mesmos por seu treinamento, sugere o funcionário do Ministério da Saúde - como já fazem engenheiros, advogados, contadores...

\section{Fala um médico}

Entre os sete convidados para a audiência, dois eram médicos que falaram de suas próprias experiências. Um deles, Thomas P. Stossel, da Escola de Medicina de Harvard, declarou-se totalmente favorável à ilimitada atuação das companhias farmacêuticas e de dispositivos médicos. Outro, Steven Nissen, disse o seguinte:

4. American Medical Association, Council on Ethical and Judicial Affairs, Ceja Report 1-A-09 Financial Relationships with Industry in Continuing Medical Education (June 5, 2009). Disponível em: <http://www.cohealthcom.org/content/library/cc/CEJA/CEJA_RecommendationJun09.pdf>. Acessado por Lewis Morris em: 18 jul 2009. 
Meu nome é Steven E. Nissen, MD. Eu sou o presidente do departamento de medicina Cardiovascular na Clínica Cleveland e ex-presidente do Colégio Americano de Cardiologia. Meu testemunho não reflete a visão da Clínica Cleveland nem do Colégio de Cardiologia.

Educação Médica Continuada, conhecida comumente como CME, foi pensada originalmente para servir como o principal meio pelo qual médicos mantem competência profissional e adquirem novos conhecimento médicos. De fato, muitos estados exigem um numero mínimo de créditos de CME como condição para a continuidade da licença para clinicar ou exercer a enfermagem. Recentemente, CME se transformou em uma indústria enorme com influência extraordinária sobre a prática da medicina. Em 1998, o dispêndio total em CME foi de US\$ 888 milhões. Em 2007, o dispêndio cresceu para mais de US\$2,5 bilhões anuais.

Idealmente, CME deveria oferecer educação equilibrada e baseada em ciência para melhorar a qualidade dos cuidados de saúde. Ao invés disso, a CME se transformou em um veículo insidioso para a promoção agressiva de drogas e dispositivos médicos. Estranhamente, 50\% do financiamento de CME, cerca de US\$ 1,2 bilhões, vem de companhias que comercializam medicamentos e dispositivos médicos. Essencialmente, as divisões de marketing dessas empresas agora dominam uma proporção substancial da educação dos médicos. CME evoluiu largamente para marketing, inteligentemente disfarçado em educação.

Uma indústria inteiramente nova foi criada, empresas de comunicação médica, frequentemente localizadas muito perto da sede das maiores companhias farmacêuticas e fabricantes de dispositivos médicos. Essas empresas solicitam financiamento da indústria para conduzir uma variedade de ofertas "educacionais”, com um ar de independência que camufla a natureza promocional dos programas educacionais. Frequentemente, o material afirma que o programa foi financiado via uma "doação educacional sem restrições" da companhia patrocinadora. No entanto, com um aceno de cabeça, as empresas de comunicação selecionam palestrantes e tópicos que, eles sabem, vão agradar os patrocinadores. Quando pego esse material, eu me dedico a um esporte interessante. Tento adivinhar qual é a companhia patrocinadora examinando a lista de palestrantes $e$ seus tópicos. Minhas adivinhações quase sempre são corretas.

Nos grandes encontros científicos, há dezenas de simpósios "satélites" patrocinados pela indústria, anunciado por meio de brilhantes e multicoloridos folhetos. Esses encontros oferecem um jantar, seguido por uma série de aulas por conhecidos e bem pagos médicos da academia. O conteúdo é artisticamente organizado pela companhia de comunicação médica para sutilmente, e não tão sutilmente, promover os produtos da patrocinadora. Se você não comparece a um 
desses encontros, pode ter acesso ao mesmo conteúdo via web. As empresas de comunicação médica que produzem esses materiais cobram centenas de milhares de dólares da indústria para organizar um simples encontro ou webcast.

Prontamente, as companhias pagam centenas de milhões de dólares anualmente para apoiar CME por uma razão simples: a educação médica continuada vende seus produtos. CME financiada pela indústria não é filantropia, é marketing. De fato, os fundos para CME vêm do orçamento de marketing da indústria. O fluxo de dinheiro é tão atrativo que agora é comum grandes centros médicos acadêmicos administrarem organizações de CME que competem com empresas de comunicação pela gerência de programas educacionais financiados pela indústria. E para não deixar de fora, muitas revistas científicas aceitam reembolsos para publicar anais de CME financiada pela indústria, via "edições especiais".

O lucrativo processo de CME também minou a independência das sociedades médicas profissionais, que podem receber mais de $50 \%$ de suas receitas da indústria farmacêutica e de dispositivos médicos. A educação médica continuada patrocinada pela indústria oferecida por meio de sociedades médicas traz o risco de que o imprimatur de uma organização prestigiada será manipulado para propósitos profissionais. Em um dos piores exemplos, uma organização muito proeminente de cardiologia criou uma "mesa-redonda farmacêutica", em que companhias que oferecem grandes doações para a organização ganham acesso privado especial a lideres da área.

Sociedades profissionais têm papel crítico na prática da medicina. São elas que escrevem as diretrizes e os padrões da prática usados por médicos para selecionar o tratamento mais apropriado para nossos pacientes. A fusão de financiamento pela indústria com as sociedades profissionais pode potencialmente prejudicar a integridade e a independência dessas organizações profissionais e levanta grandes questões sobre a objetividade das diretrizes que produzem. Recentemente, um grupo de líderes e ex-líderes de sociedades publicaram em anexo ao Jornal da Associação Médica Americana uma recomendação para que as sociedades médicas adotem uma política de financiamento zero da indústria nos próximos anos.

Há alguns poucos exemplos em que o financiamento de CME pela indústria parece atender a um padrão maior de independência, mas eles são relativamente raros. Nesses casos, um centro médico importante ou sociedade profissional conduz um programa de CME patrocinado por várias organizações comerciais, cada uma das quais contribui com uma pequena parte do financiamento.

Com bilhões de dólares da indústria fluindo na direção da CME, quem está vigiando a integridade do processo educacional? A supervisão atual da ACCME 
é em grande parte inefetiva. A ACCME dispõe de regras estritas que governam as atividades educacionais, mas parece desinteressada ou incapaz de fazer com que sejam respeitadas. Eu não sei de nenhuma empresa de comunicação médica que tenha perdido seu credenciamento por causa de CME manipulada.

De fato, em várias ocasiões escrevi à ACCME para reclamar sobre atividades inapropriadas de credenciados. Sequer o recebimento de minhas cartas foi acusado. No pior dos casos que relatei, recebi um documento por correio que se intitulava "Relatório de Consenso em Cardiologia", formatado para imitar uma diretriz de sociedade profissional. De fato, o documento foi desenhado para promover um produto específico e os autores foram pagos pela empresa de comunicação médica para "escrever" o "relatório de consenso". Nunca a ACCME respondeu à minha reclamação.

Nos anos recentes, a CME tem sido usada crescentemente para esconder pagamentos a médicos que, de outra maneira, teriam que ser declarados pelas regras de transparência dos hospitais e escolas de medicina. Uma vez que os honorários vêm de uma terceira fonte e é usado para apoiar a CME, quem recebe escapa da obrigação de declarar. Essencialmente, as companhias de comunicação médica são usadas para "lavar" dinheiro que se deveria declarar.

Como nação, gastamos quase o dobro do que gastam outros países industrializados em tratamento médico. Usamos mais medicamentos caros que outros países, mesmo depois de ajustado o gasto para nosso nível de riqueza. Estou convencido de que a máquina multibilionária conhecida como CME contribui diretamente para este excesso nos gastos com saúde.

\section{Finalmente}

O Partido Republicano dos EUA defende a perseguição a empresas do setor farmacêutico e de dispositivos médicos que promovem o uso off label de seus produtos e, dessa forma oneram ilegalmente o sistema público de saúde dos EUA, como uma das maneiras de controlar seu custo. No debate ocorrido durante 2009, os republicanos argumentaram que medidas assim poderiam ser alternativa à reforma do sistema proposta pelo presidente Barack Obama.

\section{Referências}

Senado dos EUA, Comissão Especial sobre Envelhecimento, Audiência em 29 de julho de 2009, Medical Research and Education: Higher Learning or Higher Earning? 
Disponível na rede mundial de computadores em <http://aging.senate.gov/ hearing_detail.cfm?id=316410\&>.

Depoimento de Lewis Morris, Conselheiro Chefe do Escritório do Inspetor Geral, Departamento de Saúde e Serviços Humanos, 29 de julho de 2009. Disponível em: <http://aging.senate.gov/events/hr214lm.pdf>.

Testemunho de Steven Nissen perante a Comissão do Senado sobre Envelhecimento. Disponível em: 〈http://aging.senate.gov/events/hr214sn.pdf >.

\section{Resumos}

(La multimillonaria industria de la educación médica continuada en los EEUU: una forma de interferencia a más de las empresas en la relación médico-paciente)

El artículo trata de otra forma más a través de la cual la industria impacta la clínica médica. La industria farmacéutica y de dispositivos médicos financia la actividad de Educación Médica Continuada con el objetivo de promover la utilización de tratamientos que le interesan. La Educación Médica Continuada es obligatoria en muchos estados de los EEUU para la renovación de la licencia para el ejercicio de profesiones médicas y para-médicas. El congreso de los EEUU discute cómo regular esa cuestión, en el contexto de la reforma del sistema de salud puesta en discusión por el actual gobierno el país.

Palabras clave: Industria farmacéutica, educación médica, relación médico-paciente

(L'industrie milliardaire de la formation médicale continue aux États-unis: une autre forme d'ingérence des entreprises dans le rapport médecin-patient)

Cet article traite l'une des façons dont l'industrie influence la clinique médicale. L'industrie pharmaceutique et de dispositifs médicaux finance des activités d'Éducation Médicale Continue afin de promouvoir l'utilisation de traitements de son intérêt. La Formation Médicale Continue est obligatoire dans de nombreux états américains pour le renouvellement des licences médicales et paramédicales. Le Congrès américain discute la façon de réglementer la question dans le contexte de la réforme du système de santé mise en discussion par l'actuel président.

Mots clés: Industrie pharmaceutique, formation médicale, rapport médecin-patient

(The billion-dollar industry of on-going medical education in the U.S.A.: one more ways the medical-product industry intervenes in doctor-patient relationships)

This article discusses one more way that the industry of pharmaceutics and medical devices affects medicine, namely, by financing on-going medical educational 
activities with the objective of promoting the use of treatments that are profitable to these companies. On-going medical education is required in many states of the U.S.A. as a condition for physicians to renew their licenses to practice medicine. The U.S. Congress is discussing how to regulate the matter in the context of the national health system reform now under discussion in that country.

Key words: Pharmaceutical industry, medical education, doctor-patient relationship

Citação/Citation: TeIXEIRA, M. A bilionária indústria da educação médica continuada nos EUA: mais uma forma de interferência das empresas na relação médico-paciente. Revista Latinoamericana de Psicopatologia Fundamental, São Paulo, v. 12, n. 4, p. 731-742, dez. 2009.

Editor do artigo/Editor: Mônica Teixeira e Prof. Dr. Erney Plessmann de Camargo

Recebido/Received: 30.10.2009 / 10.30.2009 Aceito/Accepted: 4.11.2009 / 11.4.2009

Copyright: (C) 2009 Associação Universitária de Pesquisa em Psicopatologia Fundamental/ University Association for Research in Fundamental Psychopathology. Este é um artigo de livre acesso, que permite uso irrestrito, distribuição e reprodução em qualquer meio, desde que o autor e a fonte sejam citados/This is an open-access article, which permits unrestricted use, distribution, and reproduction in any medium, provided the original author and source are credited.

Financiamento/Funding: A autora declara não ter sido financiada ou apoiada/The author has no support or funding to report.

Conflito de interesses: A autora declara que não há conflito de interesses/The author declares that has no conflict of interest.

\section{Mônica TeiXeira}

Jornalista; psicanalista; coordenadora geral do programa Universidade Virtual do Estado de São Paulo na TV Cultura (São Paulo, SP, Brasil); diretora de redação do boletim eletrônico Inovação Unicamp (Campinas, SP, Brasil).

Av. Higienópolis, 318/13

01238-001 São Paulo, SP, Brasil

e-mail: armonica@uol.com.br 